\title{
Erratum to: Conservation status of the only representative of infraorder Mygalomorphae (Araneae) in cultivated regions of Central Europe
}

\author{
Milan Řezáč • Petr Heneberg
}

Published online: 10 September 2014

(c) Springer International Publishing Switzerland 2014

\section{Erratum to: J Insect Conserv (2014) 18:523-537 DOI 10.1007/s10841-014-9668-y}

Due to an unfortunate mistake, two inadvertent errors were published.

In the abstract, the sentence "Nests of European Atypus species have never been found in habitats subject to recent or even regular distribution" should be replaced by "Nests of European Atypus species have never been found in habitats subject to recent or even regular disturbance".

On page 530, the following sentence, "In the beginning of the paragraph you say every year. Maybe I misunderstand 'control'. If this is not monitoring you may have to change that." should not have been included in the publication. It was mistakenly published.

The online version of the original article can be found under doi:10.1007/s10841-014-9668-y.

\footnotetext{
M. ̌̌ezáč $(\bowtie)$

Biodiversity Lab, Crop Research Institute, Drnovská 507,

16106 Prague 6-Ruzyně, Czech Republic

e-mail: rezac@vurv.cz

P. Heneberg

Third Faculty of Medicine, Charles University in Prague, Ruská

87, 10000 Prague 10, Czech Republic

e-mail: petr.heneberg@lf3.cuni.cz
} 